\title{
Rethinking Physician Payment
}

\author{
Zirui Song, MD, PhD ${ }^{1,2,3}$ and Laurence F. McMahon, Jr., MD, MPH 4,5 \\ 'Department of Medicine, Massachusetts General Hospital, Boston, MA, USA; ${ }^{2}$ Harvard Medical School, Boston, MA, USA; ${ }^{3}$ National Bureau of \\ Economic Research, Cambridge, MA, USA; ${ }^{D}$ Department of Internal Medicine, University of Michigan Medical School, Ann Arbor, MI, USA; \\ ${ }^{5}$ Department of Health Management and Policy, University of Michigan School of Public Health, Ann Arbor, MI, USA.
}

KEY WORDS: Payment; Reform; Innovation; Global budget; Value. J Gen Intern Med 30(2):152-4

DOI: $10.1007 / \mathrm{s} 11606-014-3035-2$

(c) Society of General Internal Medicine 2014

$\mathrm{C}$ urrent efforts to slow health care spending center on changing the way physicians are paid. As payers move away from fee-for-service, physician organizations are increasingly taking on contracts with population spending budgets. ${ }^{1}$ This transition revamps their business model. Revenue centers can become cost centers. Loss leaders can become opportunities for savings. With a budget in hand at the beginning of a year, physician organizations must now decide how to pay their constituent providers in a way that maximizes the value of care they deliver.

This is a difficult task amidst organizational hierarchies that reflect the fee-for-service paradigm. Across the country, many physician organizations are bracing for battles between departments and divisions for shares of a constrained budget. Paying the old way based on relative value units (RVUs) is not ideal, as volume can drive down potential savings under the budget. Paying for quality is difficult, as quality metrics outside of primary care remain underdeveloped. Splitting the global budget into mini-budgets is plausible, but determining the amount and growth rate for one practice or specialty relative to another is challenging.

Innovations in physician payment are needed, yet frameworks for how to innovate are lacking. We discuss a simple framework for thinking about innovations in physician payment.

\section{THINKING INSIDE THE BOX}

Traditionally, innovations in physician payment involved toggling one of three levers - the degree of financial risk that physicians bear, the extent of payment based on quality, and the level at which incentives are targeted - each captured on a simple continuum (Fig. 1).

On the first dimension, fee-for-service spares the physician of risk, whereas capitation places risk on the physician. For 30 years, payment oscillated between these two extremes, each having its well-known shortcomings. Accountable care

Published online September 23, 2014 organizations today vary widely on this dimension, with some facing little risk (such as the initial years of the Medicare Shared Savings Program), and others substantial risk (some private insurer contracts). Risk also manifests through bundled payments or episode-based payments, which are effectively pieces of a global budget that cover certain segments of care.

The second dimension, pay-for-performance, offsets financial risk by providing a menu of process, outcome, or patient experience targets tied to additional bonus payments. Despite its popularity, pay-for-performance remains a small part of total physician compensation. In 2012, less than $15 \%$ of payments for privately insured individuals were tied to quality.

The third dimension is the organizational level at which incentives are set. Individual- and group-level incentives motivate people in different ways. While the latter are more powerful in some contexts, ${ }^{2}$ whether they outperform individual incentives in a given clinical situation remains largely unknown.

Together, these three dimensions encase the major payment systems envisioned to date. Within this framework, current payment reforms are pushing provider organizations away from the intersection of these 3 axes - the pure RVU system for the individual-towards a group-level budget based on quality (the opposite corner of the box, not drawn).

This, however, may not be the only way forward. Conceptually, physician organizations face the question of whether their "sweet spot" for incentives exists inside the box or outside the box, where other dimensions on which to base payment might exist.

\section{THINKING OUTSIDE THE BOX}

What are other dimensions on which to base payment? Value is one. ${ }^{3}$ When value is invoked, it usually assumes the traditional form: Value $=$ Benefit/Cost. However, in most instances, our understanding of benefits and costs is fixed based on average treatment effects found in an observational study or clinical trial, with little nuance regarding clinical appropriateness for a given patient or situation. An improved value equation could be the following:

Value $=$ Appropriateness $\mathrm{x}$ Benefit $/$ Cost

This equation recognizes the clinical nuance of a medical service. The appropriateness variable could represent the 


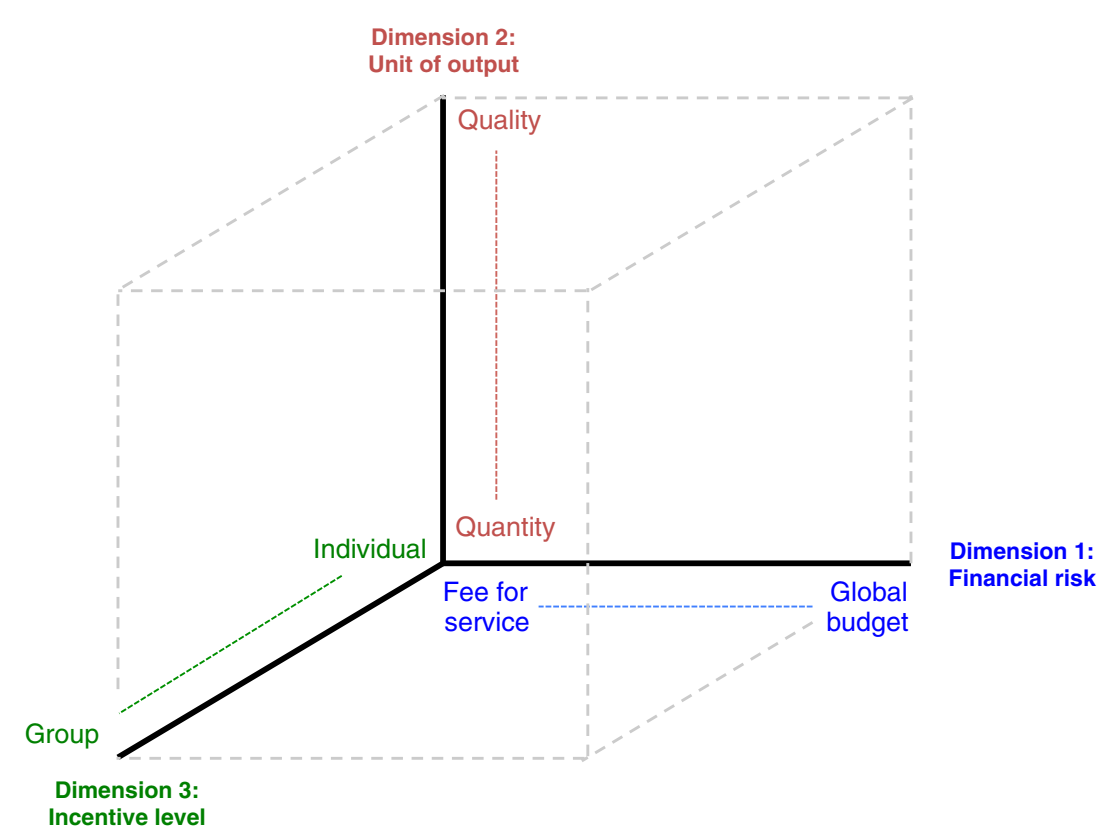

Fig. 1. The three dimensions along which innovations in physician payment have traditionally taken place: (1) the degree of financial risk that physicians bear, (2) the extent to which payment is based on quality, and (3) the level of the organization at which incentives are targeted. Current reforms are moving physicians away from the intersection of the three lines-which denotes the pure RVU system with no quality components for the individual - towards the opposite corner of the box, which captures the idea of a group-level global budget based on quality. Despite current reforms, physician payment in the U.S. remains closer to the former point than the latter.

degree to which a service is indicated. In other words, it might represent the likelihood that the benefit will be realized, given patient characteristics. For example, imaging for non-specific low back pain may differ in value from imaging for low back pain with red-flag signs. Similarly, a stent for stable angina may differ in value from a stent for unstable angina. Organizations under global budgets could determine their own appropriateness multiplier and use it to price their medical services in a more nuanced way. Although most global budget contracts still rely on the RVU fee schedule for accounting purposes, which prices a given service the same irrespective of appropriateness, it is reasonable to imagine that physician organizations can be more thoughtful and critical in setting prices for their providers. For starters, they could refer to the published lists of the American Board of Internal Medicine Foundation's Choosing Wisely Campaign.

Behavioral economics offers other dimensions. The size and timing of payment could be toggled to make incentives more salient: giving physicians rewards in smaller chunks more often changes rewards from a single, delayed gratification to a more frequent, immediate gratification. "Loss aversion" or the "endowment effect" could be used to make incentives more powerful: a portion of fees could be initially withheld, and paid upon achievement of targets at the end of a year. ${ }^{5}$ Alternatively, a group's budget could be awarded in January, with portions clawed back should attainment of quality or spending targets not occur by December. Peer pressure could empower incentives still, for example by redesigning absolute productivity on volume or quality into relative productivity across individuals or groups within the organization. While these options may have theoretical appeal, they undoubtedly face practical challenges such as securing physician buy-in. Nevertheless, for the innovative physician organization that is willing to experiment, behavioral economics offers dimensions outside the box.

Many other dimensions reside outside the box. The nature of physician work (including its cognitive or procedural demands), the extent of physician effort, and the efficiency of physician teamwork are a few. No payment system is likely to be perfect. For some physician organizations, innovations may come from finding a better mix among the three traditional dimensions. For others, innovations could come from outside the box. With roots in fee-for-service, organizations are now crucial laboratories for payment innovations that could help them succeed under global budgets and help design tools for encouraging higher value care across the health care system.

Acknowledgments: Funders: Zirui Song acknowledges support from a National Institute on Aging M.D./Ph.D. National Research Service Award (F30 AG039175).

Conflict of Interest: The authors declare that they do not have a conflict of interest.

Corresponding Author:Zirui Song, $\mathrm{MD}, \mathrm{PhD}$; Department of Medicine Massachusetts General Hospital, Boston, MA 02114, USA (e-mail: zirui_song@post.harvard.edu). 


\section{REFERENCES}

1. Frist W, Schroeder S, Report of the National Commission on Physician Payment Reform. 2013 Mar 4. (http://physicianpaymentcommission.org/report/)

2. Kullgren JT, Troxel AB, Loewenstein G, Asch DA, Norton LA, Wesby L, Tao Y, Zhu J, Volpp KG. Individual-versus group-based financial incentives for weight loss: a randomized, controlled trial. Ann Intern Med. 2013;158(7):505-14.
3. McMahon LF Jr, Chopra V. Health care cost and value: the way forward. JAMA. 2012;307(7):671-2.

4. Volpp KG, Asch DA, Galvin R, Loewenstein G. Redesigning employee health incentives-lessons from behavioral economics. N Engl J Med. 2011;365(5):388-90.

5. Skinner JS, Weinstein JN, Fisher ES. Withholds to slow Medicare spending: a better deal than cuts. JAMA. 2012;307(1):43-4. 